\title{
Experiência de fluxo e prática instrumental: dois estudos de caso
}

\author{
Flow experience and instrumental practice: two case studies
}

por Rosane Cardoso de Araújo e Margaret Amaral de Andrade

\section{RESUMO}

No presente artigo são apresentados dois estudos de caso sobre as práticas musicais de dois músicos com vivências em contextos distintos, tendo como base a Teoria do fluxo (Flow Theory) de Csikszentmihalyi. o "estado de fluxo" é uma experiência na qual o prazer no desenvolvimento de determinada atividade é proporcionado por meio do equilíbrio entre as habilidades do sujeito e o nível dos desafios enfrentados, a ponto de gerar um alto grau de concentração e satisfação pessoal. 0 objetivo geral para esta pesquisa foi verificar, nas situações de prática musical dos músicos participantes, a presença de elementos constituintes da experiência de fluxo, como a emoção, concentração, organização da prática (estabelecimento de metas). Os resultados deste estudo apontaram para a relevância dos processos auto-regulatórios como componentes essenciais da otimização da performance, que direcionam a atenção, e geram a concentração, favorecendo a vivência do fluxo.

Palavras-chave Motivação; Teoria do Fluxo; Cognição; Prática Musical

\section{ABSTRACT}

In this paper we present two case studies of musical practices of two musicians with experiences in different contexts, based on the Csikszentmihalyi's theory of flow. The state of flow is a experience in which the pleasure in the development of a particular activity is provided through the balance between the skills of the subject and the degree of challenges of the tasks as to generate a high degree of concentration and personal satisfaction. The aim for this research was to verify, in situations of musical practices of participate musicians, the presence of components of the flow experience, such as emotion, concentration, organization of practice (goal setting). The results showed the relevance of the self-regulatory processes as essential components of optimal performance, directing attention and generating the concentration, favoring the 'flow experience

Keywords Motivation; Flow Theory; Cognition; Musical Practice 
0 estudo da motivação é um tema que, segundo Bzuneck (2001) tem sido desenvolvido especialmente na área da Psicologia, relacionando motivação ao trabalho mental, como um processo cognitivo que permite compreender como o indivíduo persiste e direciona sua atenção na execução das suas atividades. Segundo Reeve (2006) as investigações sobre motivação auxiliam na compreensão sobre a capacidade de desempenho e bem estar dos indivíduos na realização das mais diversas tarefas, fornecendo respostas especialmente sobre as causas do comportamento humano, bem como por que os comportamentos variam de intensidade: "0 estudo da motivação refere-se aos processos que fornecem ao comportamento sua energia e direção" (REEVE, 2006, p.04). Para o autor, esses processos que energizam os comportamentos dos indivíduos são originários de eventos externos e de motivos internos, isto é, experiências geradas por fatores externos, necessidades, cognições e emoções.

A motivação, portanto, é um tema significativo para o estudo e compreensão de aspectos vinculados às práticas de ensino e aprendizagem, pois, segundo Reeve (2006) abrange teorias, constatações, domínios de aplicação, hipóteses, enfim, por meio de temas unificadores tais estudos favorecem a verificação dos fatores motivacionais nos estudantes, auxiliando na promoção de um ambiente de aprendizagem mais favorável.

Para 0’Neill at McPherson (2002), os estudos sobre motivação no contexto das práticas de ensino e aprendizagem musical permitem a compreensão de diferentes elementos que indicam a pesquisadores e docentes as variações decorrentes da persistência e do investimento no estudo musical; as estratégias que podem ser utilizadas para intervir no processo de aprendizagem; bem como de que forma as crianças mantém a vontade de seguir o estudo musical; dentre vários outros fatores.

Assim, ao focar o tema da persistência nas atividades musicais, a teoria do Fluxo (ou Flow Theory) é uma abordagem relevante, pois tem sido utilizada especialmente para os estudos cujo foco é a análise da qualidade do envolvimento dos sujeitos na realização de diferentes atividades. Esta teoria foi desenvolvida por Csikszentmihalyi (2003, 1999, 1996, 1992, 1990) e, de acordo com Nunes (2007), é vinculada aos estudos da Psicologia Positiva - novo paradigma da psicologia surgido especialmente a partir da década de 1990 - que atribui às emoções positivas um papel relevante na otimização do desenvolvimento humano.

Csikszentmihalyi (1999) explica que o "estado de fluxo" é gerado a partir de componentes afetivos da motivação que direcionam a execução de uma atividade, realizada com grande concentração e emoção. Segundo este autor, o fluxo ocorre quando o indivíduo está totalmente imerso na execução de uma atividade que Ihe proporciona desafio, no limiar de suas capacidades de controle, ou seja, um desafio proporcional às suas habilidades (em níveis elevados ou moderadamente elevados) (ver figura1): 


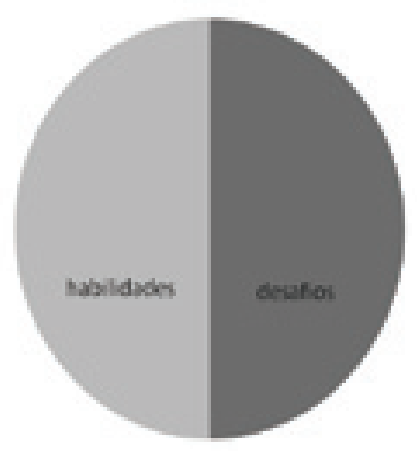

Figura 1: Relação entre desafios e habilidades para o processo do fluxo.

Segundo Reeve (2006, p. 73), o fluxo “[...] é um estado de concentração que envolve uma absorção holística em uma atividade." De acordo com este autor, a experiência vivenciada pelo sujeito durante o fluxo é de tal modo prazerosa que o indivíduo frequentemente busca a repetição da atividade para que possa vivenciar a experiência mais vezes. No contexto da prática musical, portanto, o estado do fluxo (ou experiência de fluxo, experiência de fluir) é um processo que favorece a persistência do indivíduo na sua atividade e é gerenciado por conteúdos que mantém um forte processo motivacional no indivíduo, como a emoção, as metas e as operações cognitivas (a concentração). A experiência do fluxo, portanto, é vivenciada por um engajamento do indivíduo na atividade musical que permite ao músico, por meio de um feedback imediato e positivo, a satisfação de sua necessidade de competência.

No presente artigo é apresentada uma pesquisa' realizada entre 2009 e 2010 tendo como metodologia dois estudos de caso analisados à luz da teoria do fluxo. 0 objetivo geral para a pesquisa foi verificar, por meio do relato de dois músicos sobre suas práticas musicais cotidianas, a presença de elementos descritos por Csikszentmihalyi (1999) como constituintes da experiência do fluxo. Assim foram considerados os seguintes elementos para análise: a emoção, a concentração, a organização da prática (estabelecimento de metas), e a relação entre habilidades e desafios vivenciados nas situações de execução instrumental. Os dois músicos participantes da pesquisa atuavam e estudavam em ambientes diversos: um vinculado ao ambiente da música popular, cujas atividades de performance estavam situadas em bares e shows; e outro vinculado ao ambiente das salas de concerto na prática de música antiga². Por meio de entrevistas semi-estruturadas, foram

1 A presente pesquisa foi realizada colaborativamente entre as autoras que são docentes/pesquisadoras das instituições UFPR e EMBAP, junto ao grupo de pesquisa "Processos Formativos e Cognitivos em Educação Musical" (CNPQ/UFPR), vinculado ao programa de Pós-graduação em Música da UFPR.

2 A expressão "Música Antiga", neste texto se refere ao repertório de música renascentista e barroca executada pela participante da pesquisa. 
levantados dados para caracterização dos participantes e para o reconhecimento de elementos constituintes de suas práticas musicais, relacionados ao processo do fluxo.

\section{Apresentação da pesquisa}

\section{Método e instrumento de coleta de dados}

Os estudos de caso, segundo Yin (2005) favorecem a compreensão de eventos ou fenômenos individuais que ocorrem em determinada situação/ou sujeito que se deseja investigar. Neste sentido, o foco dos dois estudos de caso realizados nesta investigação foram as práticas musicais de dois músicos profissionais com atuação em contextos diversos: uma flautista atuante em um grupo de música antiga, e um percussionista, atuante em diferentes grupos/bandas de música popular. Para a coleta de dados foram utilizadas entrevistas semi-estruturadas.

\subsection{Caracterização dos participantes da pesquisa}

Para fins do relato de pesquisa, os participantes foram identificados por meio de dois nomes fictícios: Ana e Carlos. Suas identidades foram preservadas, bem como os nomes das instituições nas quais os participantes tiveram suas formações acadêmicas e os grupos de atuação profissional. Ambos participantes moravam em Curitiba, mas eram naturais de outros estados do Brasil. As entrevistas foram realizadas entre novembro de 2009 e março de 2010. Os dois entrevistados foram convidados para participar da entrevista tendo como critério de seleção para participação do estudo, a ativa prática musical que eles possuíam e a carreira profissional exclusiva na área da música.

0 primeiro entrevistado foi Carlos, que era percussionista. Na ocasião da entrevista, tinha 28 anos. Ele começou muito cedo seus estudos musicais, tocando piano sob a orientação da mãe. Aos 11 anos ganhou uma bateria e iniciou sua aprendizagem da percussão. Seu estudo foi gerenciado por práticas de auto-aprendizagem, desvinculado de um processo formal. Neste percurso ele obteve orientações com outros bateristas/percursionistas, buscou auxílio em livros, em gravações, enfim, procurou diferentes formas para aprender o seu instrumento e desenvolver suas habilidades. Ele fez curso superior de Licenciatura em Música.

A segunda entrevistada foi Ana. Na ocasião da entrevista, Ana tinha 26 anos. Ela iniciou seus estudos de flauta doce ainda criança, com 10 anos, sob orientação de uma professora que era membro de sua família (uma tia). Segundo ela o "estudo mais sério" veio com sua decisão de fazer como curso superior o Bacharelado em Flauta Doce. Durante sua formação, no curso de bacharelado, ela teve uma grande dedicação ao estudo diário, que segundo ela era de 5 a 6 horas por dia. Após a conclusão, esta quantidade de horas de prática diminuiu um pouco, em função do 
seu trabalho (ensino de flauta doce). Para ela, a prática de ensino de flauta doce, bem como suas atividades de performance vinculadas especialmente à prática de repertório de música barroca, eram atividades muito significativas e prazerosas.

\section{Categorias analisadas: Organização da prática musical e repertório; concentração; emoção e fluxo}

Para organizar os aspectos relativos aos componentes do fluxo na prática musical dos participantes, a análise dos dados foi concebida em três itens, contendo categorias de análise, assim dispostos: A) Organização da prática/metas, desafios e contribuição do repertório; B) concentração; C) emoção e fluxo. Estas categorias foram escolhidas por serem adequadas para uma análise baseada no discurso dos entrevistados, tendo em vista que poderiam ser evidenciadas nos relatos sobre a prática musical cotidiana.

\section{Organização da prática/metas, desafios e contribuição do repertório}

Um dos aspectos discutidos por Csikszentmihalyi (1999), que caracteriza a experiência do fluxo é o estabelecimento das metas e a existência de desafios compatíveis com a capacidade do sujeito. As metas e os desafios, portanto auxiliam os processos de concentração e de organização da atividade. Segundo Reeve (2006), os desafios em níveis ótimos, isto é aqueles que instigam os indivíduos a executar tarefas dentro de suas capacidades em alto nível, geram o fluxo e um feedback positivo, isto é a percepção da competência. Já as metas, para Reeve "[...] geram motivação fazendo com que a atenção da pessoa se focalize na discrepância (ou incongruência) entre seu nível de realização [...] e seu nível ideal de realização [...]." (REEVE, 2006, p. 131).

Os dois participantes da pesquisa eram músicos que decidiram, com autonomia, seguir carreira musical, portanto existia, em ambos, um forte componente de motivação intrínseca:

Na verdade a tia me apresentou digamos "o instrumento" assim, nestas reuniões de família e assim, bem informalmente, aí eu fui gostando, fui gostando tanto que no fim acabei decidindo que era isso que eu queria mesmo. Então, ninguém me forçou, foi bem legal! [...] Aí depois, quando eu tinha uns 15 anos eu vinha para Curitiba para fazer aulas de teoria e de flauta doce... Com essa idade eu já tinha decidido que era música mesmo que eu queria fazer! (ANA, 2010, Entrevista 2, p.1).

Antes da adolescência, lá pelos 6, 7 anos eu já tava motivado pela música. Eu gostava de ouvir música, de ver os outros tocando, da profissão do músico. Prá mim isso sempre foi, sempre é muito fascinante. (CARLOS, Entrevista 1, p.1) 
Ao relatarem suas práticas musicais, foi possivel identificar elementos que indicavam que os músicos possuíam uma prática de estudo frequentemente sistematizada, baseada no estabelecimento de metas; que possuíam preferência de repertório; e que tinham experiências freqüentes de performance pública.

Ana atuava em um grupo de Música Antiga e possuía certa regularidade de participação em concertos. Ao relatar sua prática de estudo identificou um "roteiro" que desenvolvia especialmente na aquisição de um novo repertório: "Faço assim: primeiro uma leitura geral, depois faço a análise da peça, aí verifico os temas e contrapontos. Depois eu procuro ouvir diferentes gravações da obra e por último resolvo os problemas técnicos" (ANA, 2010, Entrevista 2, p. 3). Ao analisar o estudo do seu repertório já pronto, ela também indicou que, com certa freqüência, utilizava as seguintes estratégias que Ihe rendiam o controle da organização de sua prática - a) estudo de notas (ongas; b) estudo das escalas; c) estudo das peças do repertório:

Por exemplo, em época de prova do bacharelado, era sempre assim: começa notas longas, escalas e aí vêm as peças. Aí normalmente organizava o estudo das peças tocando as peças inteiras, para ter a noção do todo e depois resolvia todos os probleminhas. Então pegava os trechos piores e trabalhava eles. [...] Hoje dá pra dizer que ainda é assim. (id)

Sobre as suas preferências de execução, ela destacou as obras do repertório barroco. Segundo Ana, este repertório the rendia muita satisfação:

Ah!! Eu me sinto muito bem!! [...] A eu sou apaixonada por música barroca... Eu sei que eu precisaria, digamos, para ser uma musicista mais completa, tocar mais música medieval e mais música contemporânea. Música contemporânea a gente até fez no quarteto do quarto ano superior [...] mas eu também precisaria estudar mais "solo" de música contemporânea. (ANA, 2010, Entrevista 2, p. 4).

Ela revelou que sentia necessidade de trabalhar mais com o repertório de música contemporânea e de música medieval e que os maiores desafios de sua prática eram encontrados no repertório de música barroca e nas obras de música contemporânea. Assim, ao refletir sobre o seu procedimento de aquisição de um novo repertório, ela explicou que procedia em pequenas etapas, ou seja, estabelecia pequenas metas para dominar as peças mais complexas. E, ao avaliar sua sensação sobre a conquista das pequenas partes do novo repertório, ela expressou que isso Ihe rendia uma grande satisfação: "Ai eu me sinto muito bem, muito feliz assim, sabe? É como se viesse a mente os momentos felizes"... (id.)

Carlos, por sua vez, também apresentou em seu discurso, elementos que revelaram que este possuía um controle do seu estudo, seja para novo repertório, seja para prática do repertório já estudado:

Hoje é bem complicado para estudar bateria é bem complicado porque eu moro num apartamento. Mas eu estou sempre tocando, toco quase 
todas as noites com os grupos. Isso é uma prática diária. (CARLOS, Entrevista 1, p. 3).

Como músico de banda, ensaiava com frequencia com vários grupos e se apresentava muito, em bares e shows. Ao relatar o seu processo de estudo, ele enfatizou especialmente a aquisição das peças novas, nas quais ele estudava por partes "[...] tentando..., adicionando de pedacinho em pedacinho... "(CARLOS, 2009, entrevista 1, p. 02). até conseguir a execução do todo. Na sequencia, ele explicou o processo pelo qual como conseguia o bom desempenho na execução, isto é, a prática deliberada, cotidiana: "Aí... toca, toca, toca...muito, muito" (Ibid., p.03). Segundo ele, esta prática the garantia um controle e segurança sobre o repertório: "[...] o repertório fica sempre em dia" (id).

Ao tratar de sua preferência de repertório, ele destacou a grande alegria e desafio que a execução da música brasileira Ihe trazia, especialmente o samba e a bossa-nova:

Precisa ser versátil. Você tem que saber tocar samba, você tem que saber tocar roque, tocar jazz, música latina. É isso [...] Não dá para ser chegar mais ou menos. Dominar estas linguagens, estes gêneros musicais é importante [...] Então é claro que o e estilo que eu gosto mais é do repertório de música brasileira [...] especialmente samba e bossa nova. (CARLOS, Entrevista 1, p. 4)

Segundo ele, este repertório, bem como aquele de música latina, possuía grande complexidade rítmica para o baterista e ele se sentia constantemente desafiado. Além disso, ele relatou como um dos desafios que lhe proporcionavam grande satisfação era a participação em grupos compostos por músicos de alto nível de desempenho. Isso lhe rendia muita motivação na sua prática, pois se sentia muito desafiado e comprometido com sua performance.

Para ambos entrevistados, portanto, os componentes da experiência do fluxo metas e desafios, assim como o tipo do repertório executado, eram elementos que Ihes permitiam manter sempre um significativo grau de motivação intrínseca para a organização de seus estudos, seja na aquisição de um novo repertório ou na manutenção de um repertório já consolidado. No entanto também é possível verificar que, frequentemente, os músicos precisavam tomar decisões com base em situações de motivação extrínseca que gerenciavam decisões sobre o tipo do repertório bem como sobre o contexto da prática.

\section{A concentração}

Analisando o relato sobre a prática musical dos dois participantes, foi possível verificar em seus discursos elementos que indicavam que, durante suas práticas cotidianas - estudo e performance pública - existiam momentos de grande concentração. Ambos relataram estes momentos, identificando situações específicas em que percebiam que este aspecto era mais evidente. Para Carlos, por exemplo, 
sua concentração era grande, especialmente na aquisição de um novo repertório, no entanto a experiência descrita por Csikszentmihalyi (1999) como a "perda da noção de tempo" (ou perda da autoconsciência) era muito forte no contexto de grupo. Numa de suas observações, sobre sua prática com um dos grupos, ele relatou:

o tempo todo [...] de pegar assim uma música e vai, vai, sem ver o tempo passar. Na prática, hoje, tem vezes que você tá fazendo um repertório que você domina, mas tá fazendo com músico que você nunca tocou [...] Que nem na semana passada que eu toquei com uns músicos... "Tops". Então assim, a gente tocou por duas horas e as duas horas passaram como se fossem 15 minutos! (CARLOS, 2009, entrevista 1, p. 04).

Ele percebia, portanto, que em muitos casos a experiência com o grupo era vivenciada intensamente com uma sensação de "concentração conjunta", onde ele sentia como um momento particular:

E aí acontece um diálogo, um movimento [...]. É uma conversa que acontece entre os músicos, mas ninguém fala nada. E isso, assim, é muito interessante na música. Quando acontece é mágico (id).

Ana também identificou aspectos referentes à perda da noção de tempo em sua prática musical. Segundo ela, em seu estudo cotidiano frequentemente precisava usar um relógio despertador para lembrá-la de terminar seu estudo, quando tinha outros empenhos, pois sua imersão na atividade era muito profunda e realmente a distanciava do controle temporal. Ela recordou outros exemplos de momentos em que esta mesma intensidade de concentração era vivenciada em situação de aula (durante o período em que tinha aulas de flauta na faculdade) e também com seu grupo de música antiga. Ao lembrar, por exemplo, de uma aula que teve com um renomado professor de flauta doce, ela relatou que ao invés de durar uma hora, a lição demorou três horas, sem que ninguém se importasse com o tempo: “[...] então a aula era pra durar uma hora, mas no fim durou três horas de tão 'encantados' que nós estávamos" (ANA, 2010, entrevista 2, p.03). E sobre sua experiência com seu grupo de música antiga, ela também comentou:

"Ah! Eu tive experiências maravilhosas com os colegas...Era um repertório que a gente curtia muito fazer...Nossos ensaios nunca acabavam na hora... nunca tínhamos um horário para terminar." (Ibid., p. 03).

\section{Emoção e Fluxo}

A emoção é um dos componentes essenciais da experiência do fluxo. Para Csikszentmihalyi (1999), as emoções positivas são estados interiores de consciência nas quais a energia psíquica pode fluir livremente. As emoções, metas, concentração, motivação, por sua vez, quando combinadas numa determinada atividade, podem gerar um êxtase, isso é, o fluxo. 
Em ambos participantes a emoção foi relatada durante suas entrevistas. Com pequenas frases os participantes demonstraram elementos emotivos referentes às suas práticas musicais. Ana apresentou os seguintes termos ao relatar algumas de suas práticas musicais: "uma experiência maravilhosa"; "muita felicidade"; "percebi que eu dei conta!". Carlos, por sua vez, de forma semelhante à Ana, expressou suas impressões sobre momentos da execução musical: "é mais do que feliz"; "transborda"; "é um momento de êxtase", "me sinto competente!".

Os elementos de emoção relatados pelos participantes, portanto, são compatíveis com os indicativos da experiência do fluxo descrita por Csikszentmihalyi (1999), ou seja, as emoções experimentadas pelos participantes podem ser descritas como fenômenos subjetivos, expressivos que, de acordo com Reeve (2006, p. 04) "orquestram a maneira como reagimos adaptativamente aos eventos importantes de nossas vidas".

Assim, tendo em vista que a prática musical de Ana e Carlos era organizada com fortes elementos de emoção, concentração, sistematização/metas, foi possível concluir que estes componentes geravam, com muita freqüência durante as suas práticas musicais, a experiência do fluxo. Consequentemente, esta experiência os instigava a querer, cada vez mais, desenvolver suas habilidades como músicos, buscar novos desafios, enfim, manter elevados níveis motivação, pois os dois músicos possuíam um feedback muito positivo de suas práticas, ou seja, de modo geral, eram muito satisfeitos com seus desempenhos. Tal feedback positivo de desempenho, para Csikszentmihalyi (1999), é um dos aspectos fundamentais na experiência do fluxo, que, segundo Reeve (2006, p. 76) "fornece as informações de que as pessoas precisam para formular uma avaliação cognitiva de seu nível percebido de competência".

\section{Conclusão}

Os dois estudos de caso apresentados neste texto possibilitam evidenciar, no contexto da prática musical, elementos sugestivos para a compreensão de fatores que possibilitam vivenciar a experiência do fluxo. Dentre os dados analisados nos dois casos, foi possível encontrar componentes significativos da experiência, relatados pelos participantes como: as metas (na organização do estudo e no gerenciamento dos desafios); a concentração (nas atividades de estudo e performance em grupo e individual); e a emoção (como feedback positivo da atuação musical dos participantes).

Estes dados, portanto, tem grande significado no contexto do ensino e prática musical, pois podem auxiliar músicos e docentes a compreender os mecanismos que levam com freqüência à permanência ou abandono das práticas musicais de crianças, jovens e adultos. A satisfação com a prática e a experiência positiva, neste caso, a experiência de fluxo, favorecem o desenvolvimento do sentimento de 
Experiência de fluxo e prática instrumental: dois estudos de caso

competência e consequentemente 0 aumento da auto-estima para que 0 indivíduo se mantenha motivado em sua atividade musical. 


\section{Referências Bibliográficas}

> BZUNECK, José A. A motivação do aluno: aspectos introdutórios. In: BORUCHOVITCH, E.; BZUNECK, J. (orgs). A motivação do aluno: contribuições da Psicologia Contemporânea. Petrópolis: Vozes, 2001, p. 03.

> CSIKSZENTMIHALYI, Mihalyi. Flow: The psychology of Optimal Experience. New York: Harper đa Row, 1990.

A psicologia da felicidade. São Paulo: Saraiva, 1992.

Invention. New York: Harper Collins, 1996. $>$ A descoberta do fluxo. Psicologia do envolvimento com a vida cotidiana. Rio de Janeiro: Rocco, 1999. $>$ Good Business: Flow, Leadership and Making of Meaning. New York: Viking, 2003.

$>$ NUNES, Patrícia . Psicologia Positiva. In: Psicologia: 0 Portal dos Psicólogos. Disponível em: http://www.psicologia.pt/artigos/textos/TL0115.pdf, 2010.

> O`NEILL S.; MCPHERSON, G. Motivation. In: PARNCUTT R.; MCPHERSIN, G. (orgs). The science i psychology of music performance: creative strategies for teaching and learning. New York: Oxford University Press, 2002, p..31-46.

> REEVE, Johnmarshall. Motivação e Emoção. 4.ed. Rio de janeiro: LTC, 2006.

> YIN, Robert. K. Estudo de caso: Planejamento e Métodos. 3.ed. Porto Alegre: Artmed, 2005.

Rosane Cardoso de Araújo, Professora da área de Educação musical e cognição dos cursos de graduação e de pós-graduação da UFPR.

rosanecardoso@ufpr.br

Margaret Amaral de Andrade, Professora da área de Educação Musical dos cursos de graduação e de pós-graduação da Escola de Música e Belas Artes do Paraná (EMBAP)

meg.andrade@terra.com.br 